(อ) OPEN ACCESS

\title{
Equality of opportunity is linked to lower mortality in Europe
}

\author{
Alexi Gugushvili (ㄷ) , ${ }^{1,2}$ Caspar Kaiser (1) ${ }^{1}$
}

- Additional material is published online only. To view please visit the journal online (http://dx.doi.org/10.1136/ jech-2019-212540)

${ }^{1}$ Department of Social Policy and Intervention and Nuffield College, University of Oxford, Oxford, UK

${ }^{2}$ Erasmus School of Social and Behavioural Sciences, Erasmus University Rotterdam, Rotterdam, The Netherlands

\section{Correspondence to}

Dr Alexi Gugushvili, Erasmus

School of Social and Behavioural Sciences, Erasmus University

Rotterdam, Postbus 1738, 3000

DR Rotterdam, The Netherlands; gugushvili@essb.eur.nl

Received 15 April 2019 Revised 28 August 2019 Accepted 9 October 2019 Published Online First

5 November 2019

\section{Check for updates}

(C) Author(s) (or their employer(s)) 2020. Re-use permitted under CC BY-NC. No commercial re-use. See rights and permissions. Published by BMJ.

To cite: Gugushvili A,

Kaiser C. J Epidemiol

Community Health

2020;74:151-157

\begin{abstract}
Background This study investigates if intergenerational equality of opportunity is linked to mortality in 30 European countries. Equality of opportunity may lead to greater returns on health investments and, consequently, improved health outcomes. In turn, a perceived lack of fairness in the distribution of life chances and limited possibilities for upward intergenerational mobility can cause anxiety among individuals and gradually compromise their health.
\end{abstract}

Methods We used information on 163467 individuals' and their parents' Socio-Economic Index of Occupational Status from a large survey data set-the European Social Survey - to generate three complementary measures of equality of opportunity. We then linked these to administrative data on total, gender-specific and causespecific mortality rates assembled by Eurostat from the national statistical offices.

Results We found that lower equality of opportunity, measured by the attainment of individuals from the lowest and highest quartiles of socioeconomic status and by the overall intergenerational correlation in socioeconomic status, was related to higher mortality rates, particularly in relation to diseases of the nervous system and the sense organs, diseases of the respiratory system and external causes of mortality. Our measures of equality of opportunity were more consistently linked with mortality of men than women.

Conclusion Equality of opportunity may be an important explanation of mortality that warrants further research. Measures that aim at facilitating intergenerational social mobility can be justified not only via normative considerations of equality of opportunity but also in terms of individuals' chances to enjoy healthy lives.

\section{INTRODUCTION}

For the best part of the 20th century, children in western welfare democracies could expect to do far better than their parents in terms of educational attainment, income and wealth, but in many countries this is no longer the case. ${ }^{12}$ One of the proposed explanations for this trend is an inverse relationship between income inequality and social mobility. ${ }^{34}$ The recent availability of high-quality data on intergenerational income mobility in the USA $^{56}$ has also allowed social epidemiologists to investigate the links between economic opportunity and health. ${ }^{7-9}$ These studies suggest that various health outcomes, including rates of mortality, are better in counties with greater income mobility. It is unclear, however, whether these associations also hold in other countries.
In this study, we investigate if equality of opportunity is linked to mortality in Europe. We are not aware of any studies on this topic at a population level, but there is an established research tradition on the health consequences of individuals' social mobility experiences. ${ }^{1011}$ However, it is unknown how individual-level experiences translate into macro-level associations between equality of opportunity and mortality. We are therefore interested in not only how individuals' health is affected by experiencing intergenerational social mobility but also whether there are spillover effects of living in environments with varying levels of opportunities. In fact, the notion of equality of opportunity is a relative concept and its potential effect on health can be only explored on a societal level.

The concept of equality of opportunity may encompass many dimensions other than intergenerational social mobility. In this study, however, we operationalise equality of opportunity with the degree to which parental socioeconomic status is associated with children's socioeconomic status in adult life. Two main mechanisms have previously been proposed to explain a possible association between equality of opportunity and health. First, according to the economic theory of health capital, individuals have an incentive to invest in their health to realise potential gains from being healthy. ${ }^{12}$ Perceptions of equality of opportunity in more socially fluid environments may increase health investments among individuals from disadvantaged backgrounds because future possibilities make it more likely that the socioeconomic benefits of being healthier such as obtaining a quality job with high salary will actually materialise. ${ }^{8}$ Second, as the degree of social integration at a societal level plays a pivotal role for health, ${ }^{13}$ a perceived lack of fairness in the distribution of life chances and limited possibilities for upward intergenerational mobility can cause anxiety among individuals ${ }^{14}$ and gradually compromise their health. ${ }^{7}$

The studies on the USA found that the average rank in the national income distribution attained by individuals born to families in the bottom national income quartile is negatively associated with mortality. However, a number of questions remain unanswered. First, are opportunities of the most disadvantaged individuals driving these results or is equality of opportunity for all related to mortality? Second, are there gender differences in these associations? Third, what specific mechanisms link equality of opportunity and mortality? To answer these questions, we make use of a large survey data set to generate three complementary measures of equality of opportunity and link them 


\begin{tabular}{|c|c|c|c|c|}
\hline & Mean & SD & Min & Max \\
\hline \multicolumn{5}{|l|}{ Dependent variables } \\
\hline In death rate (total) & 5.9 & 1.36 & 3.58 & 9.39 \\
\hline In death rate (females) & 5.5 & 1.44 & 3.06 & 9.30 \\
\hline In death rate (males) & 6.2 & 1.36 & 3.84 & 9.65 \\
\hline \multicolumn{5}{|l|}{ Key explanatory variables } \\
\hline $\begin{array}{l}\text { Mean achievement of bottom } \\
\text { parental quartile }\end{array}$ & 40.0 & 5.49 & 18.7 & 73.1 \\
\hline $\begin{array}{l}\text { Mean achievement of top parental } \\
\text { quartile }\end{array}$ & 63.7 & 5.51 & 34.6 & 87.7 \\
\hline $\begin{array}{l}\text { Correlation in socioeconomic status } \\
\text { across parental and children's } \\
\text { generation }\end{array}$ & 0.32 & 0.11 & -0.64 & 0.83 \\
\hline \multicolumn{5}{|l|}{ Controls } \\
\hline Mean children's social status & 42.4 & 3.74 & 24.5 & 52.6 \\
\hline Mean parental social status & 40.5 & 5.72 & 22.7 & 54.8 \\
\hline Proportion of females & 52.1 & 5.09 & 32.7 & 87.7 \\
\hline Proportion with higher education & 28.2 & 13.8 & 0.00 & 71.3 \\
\hline Mean household income & 10.7 & 0.88 & 7.44 & 16.9 \\
\hline Proportion of unemployed & 6.06 & 5.16 & 0.00 & 34.5 \\
\hline Mean social trust & 4.80 & 0.74 & 2.56 & 7.99 \\
\hline Proportion of ethnic minority & 4.75 & 4.11 & 0.00 & 30.9 \\
\hline Proportion religious & 63.6 & 19.6 & 10.2 & 100.0 \\
\hline Proportion married & 64.9 & 15.1 & 8.55 & 94.1 \\
\hline Proportion living in city & 64.0 & 10.5 & 22.9 & 97.2 \\
\hline Mean political attitude & 4.98 & 0.49 & 2.83 & 6.87 \\
\hline Mean household size & 2.81 & 0.66 & 1.29 & 4.85 \\
\hline $\begin{array}{l}\text { Proportion of households with } \\
\text { children }\end{array}$ & 46.4 & 25.4 & 0.00 & 92.0 \\
\hline Proportion doing housework & 21.1 & 12.0 & 0.00 & 73.6 \\
\hline \multicolumn{5}{|l|}{ Further variables of interest } \\
\hline Mean age & 50.2 & 15.3 & 26.4 & 82.4 \\
\hline Year & 2006.1 & 2.83 & 2002.0 & 2010.0 \\
\hline $\begin{array}{l}\text { Number of individual observations } \\
\text { in macro-level observations }\end{array}$ & 161.8 & 57.7 & 9.00 & 323.0 \\
\hline
\end{tabular}

Total number of observations is 1200 . Mean column reports averages of the means/ proportions for year, age group and country combinations. Death rates taken from Eurostat, all other variables taken from ESS. For ESS data, means and SD are computed using population and design weights. ISEI scores are derived using the ISKO Stata package and coding from the ESS-DEVO project. ${ }^{40}$ Real household incomes are derived by taking the midpoints of the categorical show cards given to participants in the ESS survey. We then convert these values to 2010 EURs. For top values for which no mid-points are available, we make use of a procedure described in previous research. ${ }^{41}$

ESS, European Social Survey; ISEI, International Socio-Economic Index of Occupational Status.

to administrative data on mortality derived from the national statistical offices of the analysed European countries.

\section{METHODS}

\section{Data sets}

We obtained data from two types of sources. First, we used five waves of the nationally representative European Social Survey (ESS) collected in 2002-2010. These data provided us with 163467 individual-level observations from which we derived explanatory variables. For our outcome variables, we used data on mortality rates from national administrative sources assembled by Eurostat (see online supplementary materials table S1). Although we could not obtain information on deaths specifically for those individuals included in ESS, to match ESS and mortality data we gathered biennial death rates for 12 five-year age groups from 25 to 84 , which were nested in 30 countries (see online supplementary table S2 in online supplementary materials). We calculated quantities of interest from ESS for each survey year, age group and country for which Eurostat mortality data were available. After listwise deletion of observations with missing information, 1200 observations remained for our analysis. The distribution of cell sizes used to compute these survey year-age group-country observations, together with relevant statistics, is shown in online supplementary material, figure S1. To ensure representativeness, we applied design (accounting for differences in inclusion probabilities) and population (correcting for different population sizes) weights for ESS data and population weights for administrative mortality data.

\section{Explanatory variables}

We operationalised equality of opportunity as intergenerational mobility in socioeconomic status, assuming that the degree to which individual socioeconomic status depends on parental socioeconomic status is a good indicator of equality of opportunity. ${ }^{15}$ We measured parental and individual socioeconomic status with the International Socio-Economic Index of Occupational Status (ISEI). ISEI scores are widely used in comparative social and health research and were originally derived by estimating values of a latent variable determined by occupation which minimised the direct effect of education on income. ${ }^{16} 17$

For our first measure of equality of opportunity, we calculated the mean percentile in the socioeconomic status distribution attained by the children's generation whose parents were in the bottom quartile of the parental distribution. This measure closely corresponds to the measure of equality of opportunity used in the studies for the USA. ${ }^{78}$ We also calculated analogous quantities, recently employed in the World Bank's study of mobility, ${ }^{2}$ relating to those in the top quartile of the parental distribution. In addition, we calculated standard correlation coefficients between parental socioeconomic status percentile and children's socioeconomic status percentile. ${ }^{3}$ We calculated all quantities of interest within each year, age group and country combination.

\section{Outcome measures}

Our main outcome variable was the 3-year moving average of crude all-cause death rates per 100000 individuals. This is obtained for each age group and for each year under consideration. We additionally obtained all-cause death rates separately for men and women and death rates specific to major groupings in the 10th Revision of International Statistical Classification of Diseases and Related Health Problems (ICD-10).

\section{Covariates}

In adjusted models, for each age group, year and country combination, we generated from ESS a large array of covariates known to be associated with mortality: mean socioeconomic status in both the parental and children's generations ${ }^{18}{ }^{19}$; the proportions of females and those who were married ${ }^{2021}$; the proportion of those with higher education, mean levels of unemployment, proportion performing domestic work and mean real log household income $\mathrm{e}^{22-24}$; the proportion of individuals who live in cities ${ }^{25}$; mean household size ${ }^{26}$ and proportion of individuals with children ${ }^{27}$; mean social trust $\mathrm{t}^{28}$ and mean position on a subjective left-right scale ${ }^{29}$; the proportion of people from ethnic minorities ${ }^{30}$ and the proportion of religious individuals. ${ }^{31}$ 
Table 2 Equality of opportunity and mortality

\begin{tabular}{|c|c|c|c|c|}
\hline & $\boldsymbol{\beta}(\mathrm{Cl} 95 \%)$ & $\begin{array}{l}\text { Change in death rate from } \\
1 \text { SD change in equality of } \\
\text { opportunity, \% }\end{array}$ & $\begin{array}{l}\text { Change in death rate from } \\
\text { complete absence of equality } \\
\text { of opportunity to full equality } \\
\text { of opportunity, \% }\end{array}$ & $\mathrm{R}^{2}$ \\
\hline & \multicolumn{4}{|c|}{ Achievement of bottom quartile } \\
\hline \multicolumn{5}{|l|}{ Total death rate } \\
\hline M1: Unadjusted & $-0.20^{*}(-0.34$ to 0.06$)$ & -1.08 & -9.42 & 0.01 \\
\hline M2: Adjusted & $-0.22^{*}(-0.35$ to 0.10$)$ & -1.23 & -10.6 & 0.09 \\
\hline \multicolumn{5}{|l|}{ Females } \\
\hline M3: Unadjusted & $-0.08(-0.22$ to 0.07$)$ & -0.42 & -3.77 & 0.01 \\
\hline M4: Adjusted & $-0.16^{*}(-0.27$ to 0.04$)$ & -0.86 & -7.54 & 0.22 \\
\hline \multicolumn{5}{|l|}{ Males } \\
\hline M5: Unadjusted & $-0.24^{*}(-0.40$ to 0.09$)$ & -1.32 & -11.4 & 0.01 \\
\hline \multirow[t]{2}{*}{ M6: Adjusted } & $-0.25^{*}(-0.39$ to 0.11$)$ & -1.38 & -11.9 & 0.07 \\
\hline & \multicolumn{4}{|c|}{ Achievement of top quartile } \\
\hline \multicolumn{5}{|l|}{ Total death rate } \\
\hline M1: Unadjusted & $0.16(-0.025$ to 0.352$)$ & 0.91 & -8.52 & 0.01 \\
\hline M2: Adjusted & $0.18+(0.007$ to 0.352$)$ & 0.99 & -9.38 & 0.08 \\
\hline \multicolumn{5}{|l|}{ Females } \\
\hline M3: Unadjusted & $0.07(-0.102$ to 0.244$)$ & 0.39 & -3.61 & 0.01 \\
\hline M4: Adjusted & $0.10(-0.039$ to 0.246$)$ & 0.57 & -5.31 & 0.21 \\
\hline \multicolumn{5}{|l|}{ Males } \\
\hline M5: Unadjusted & $0.18(-0.036$ to 0.400$)$ & 1.01 & -9.54 & 0.01 \\
\hline \multirow[t]{2}{*}{ M6: Adjusted } & $0.21+(0.005$ to 0.408$)$ & 1.14 & -10.9 & 0.06 \\
\hline & \multicolumn{4}{|c|}{ Correlation of parental and child achievement } \\
\hline \multicolumn{5}{|l|}{ Total death rate } \\
\hline M1: Unadjusted & $0.09+(0.01$ to 0.17$)$ & 0.98 & -9.11 & 0.01 \\
\hline M2: Adjusted & $0.10^{*}(0.02$ to 0.18$)$ & 1.13 & -10.5 & 0.09 \\
\hline \multicolumn{5}{|l|}{ Females } \\
\hline M3: Unadjusted & $0.03(-0.04$ to 0.10$)$ & 0.31 & -2.81 & 0.01 \\
\hline M4: Adjusted & $0.06+(0.01$ to 0.13$)$ & 0.74 & -6.76 & 0.22 \\
\hline \multicolumn{5}{|l|}{ Males } \\
\hline M5: Unadjusted & $0.11^{*}(0.01$ to 0.20$)$ & 1.21 & -11.3 & 0.01 \\
\hline M6: Adjusted & $0.11^{*}(0.03$ to 0.20$)$ & 1.30 & -12.2 & 0.06 \\
\hline
\end{tabular}

Total number of observations is 1200 . Cls are computed using heteroskedasticity-robust SEs corrected for clustering at the age group-year level. Regressions are population weighted. Regressors from ESS are additionally design-weighted. Unadjusted estimates include year, age group and country fixed effects. Adjusted estimates additionally include all controls described in Methods section and in table 1. Respective absence of equality of opportunity is defined as a mean achievement of 12.5 of those coming from the bottom quartile, or a mean achievement of 87.5 of those coming from the top quartile, or a correlation of 1 between achievement in parental generation and achievement in children's generation. Respective full equality of opportunity is defined as a mean achievement of 50 of those in the bottom quartile, or a mean attainment of 50 of those coming from the top quartile, or a correlation of 0 between attainment in parental generation and attainment in children's generation. Reported $R^{2}$ are 'within' $R^{2}$. Significant associations (uncorrected, at $5 \%$ level) are shown in bold. Analyses were conducted using the REGHDFE Stata package. ${ }^{42}$

*Significant at table-wide false discovery rate of $5 \%$ (using Benjamini-Hochberg method).

tSignificant at a table-wide false discovery rate of $10 \%$.

ESS, European Social Survey.

\section{Statistical analysis}

Given substantial unobserved variation across survey years, age groups and countries, we include fixed effects for each of these variables that account for period, cohort and context-specific characteristics, respectively. Since death rates are log-normally distributed across age, we worked with the natural logarithm of mortality. After fitting models with all-cause mortality for both genders combined, we ran models with mortality rates separately for men and women. We also tested how equality of opportunity was associated with specific causes of mortality. Throughout, we calculated heteroscedasticity-robust standard errors (SEs) clustered at the age group and year level. ${ }^{32}$ In addition to standardly used confidence intervals (CIs), we also present information on whether reported coefficients are significant at a $10 \%$ or $5 \%$ table-wide false discovery rate using the Benjamini-Hochberg method. The exact specifications of our models are described in online supplementary materials, page 1 .

In further models, we accounted for leads of equality of opportunity as measured by individuals who were 5 and 10 years older than the groups whose mortality was under consideration. We also tested how lags in equality of opportunity, as measured by groups 5 to 10 years younger, affect contemporaneous mortality rates. Our reason for employing this procedure is as follows. If the theoretical perspective was correct that the mortalityreducing effect of equality of opportunity runs via increased health investments due to anticipation of upward mobility, we had to expect that leads in equality of opportunity also had negative effects on mortality. If, however, the alternative perspective 
was more accurate, that the effects of equality of opportunity run via reducing long-lasting stress, anxiety and feelings of unfairness, we had to expect that lags in equality of opportunity negatively affect mortality outcomes.

\section{RESULTS}

\section{Equality of opportunity in Europe}

The mean score of our first measure of equality of opportunity was 40.0 (min-max 18.7-73.1; see table 1 ). This means that individuals born to parents situated in the lowest quartile of the distribution in socioeconomic status can expect to find themselves in the 40th percentile of their generation's social status distribution. A complete absence of equality of opportunity would yield a mean attainment in the 12.5 th percentile (the expected percentile of children with parents in the bottom 25 th percentile when parental percentile perfectly predicts children's percentile). Further, mean attainment of those born to parents in the highest quartile of the distribution in socioeconomic status was 64.0. Perfect equality of opportunity would yield a mean attainment in the 50th percentile (the expected percentile when children's percentile is independent of parental percentile), indicating that opportunity was unequally distributed at both the lower and higher end of socioeconomic status. Similarly, we observed a mean correlation between parental and children's social status of 0.32 . Perfect equality of opportunity would imply a zero expected correlation. We could not identify obvious trends in any of our measures of equality of opportunity across years and age groups (see online supplementary figures S2-S4 in online supplementary materials).

\section{Associations between equality of opportunity and mortality}

Table 2 shows point estimates for our three measures of equality of opportunity when the outcome variable was total all-cause logged mortality rates; estimates for these measures are also shown separately by gender. Both the first and third measure of equality of opportunity had statistically significant associations with mortality in the unadjusted models. We found that a $1 \mathrm{SD}$ increase in achievement for the bottom quartile was associated with a $1.1 \%$ decrease in the total mortality rate $(\beta=-0.20$, $\mathrm{CI}=-0.34$ to -0.06$)$. In model 2 , which adjusts for the covariates, this association was even stronger with a regression coefficient of $-0.22(\mathrm{CI}=-0.35$ to -0.10$)$. Attainment of the top quartile was significantly and positively related to mortality in the adjusted model $2(\beta=0.18, \mathrm{CI}=0.01$ to 0.35$)$ only. The correlation coefficient of socioeconomic status between parents and offspring was significantly and positively associated with mortality rates in both models. Results for model 2 implied a $10.5 \%$ reduction in mortality when moving from complete absence of, to full equality of opportunity $(\beta=0.10, \mathrm{CI}=0.02$ to 0.18 )

We also performed separate analyses for men and women. For women, the coefficients of equality of opportunity were only significant in adjusted models for the attainment of bottom quartile and intergenerational correlation of socioeconomic status. For men, we found statistically significant associations in models for all three measures of equality of opportunity. Moreover, in adjusted models, the magnitude of the coefficient was higher for men (eg, in model 6: $\beta=-0.25, \mathrm{CI}=-0.39$ to -0.11 ) than for women (in model 4: $\beta=-0.16, \mathrm{CI}=-0.27$ to -0.04 ).

\section{Equality of opportunity and causes of mortality}

Table 3 shows how our three measures of equality of opportunity were associated with mortality rates for eight major causes

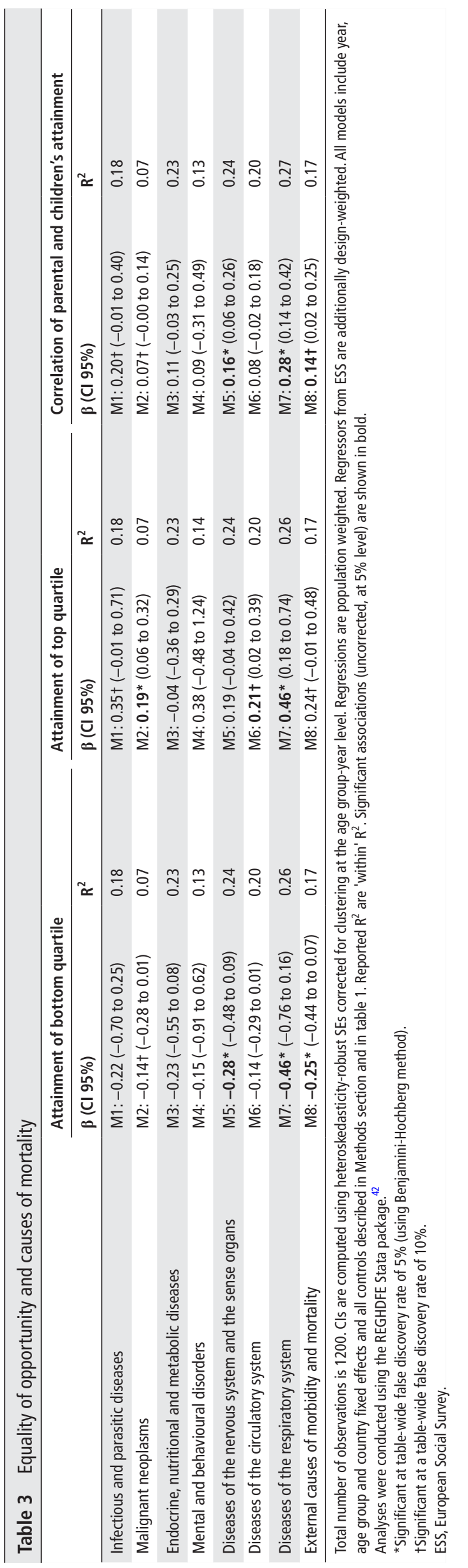


Table 4 Lags and leads in equality of opportunity and mortality

\begin{tabular}{|c|c|c|c|c|c|c|}
\hline & \multicolumn{2}{|c|}{ Attainment of bottom quartile } & \multicolumn{2}{|c|}{ Attainment of top quartile } & \multicolumn{2}{|c|}{$\begin{array}{l}\text { Correlation of parental and children's } \\
\text { attainment }\end{array}$} \\
\hline & $\beta(\mathrm{Cl} 95 \%)$ & $\mathrm{R}^{2}$ & $\beta(\mathrm{Cl} 95 \%)$ & $\mathrm{R}^{2}$ & $\boldsymbol{\beta}(\mathrm{Cl}$ 95\%) & $\mathrm{R}^{2}$ \\
\hline \multicolumn{7}{|c|}{ Lags of equality of opportunity } \\
\hline Contemporaneous & $\mathrm{M} 1:-0.23^{*}(-0.36$ to 0.10$)$ & & $\mathrm{M} 1: 0.28^{*}$ (0.11 to 0.46$)$ & & M1: $0.13 *(0.05$ to 0.20$)$ & \\
\hline Five years younger & $\mathrm{M} 1:-0.21 *(-0.37$ to 0.05$)$ & & $\mathrm{M} 1: 0.25 *$ (0.08 to 0.43$)$ & & M1: $0.12 *(0.05$ to 0.20$)$ & \\
\hline Ten years younger & $\mathrm{M} 1:-0.28^{*}(-0.45$ to 0.12$)$ & & $\mathrm{M} 1: 0.10(-0.07$ to 0.27$)$ & & $\mathrm{M} 1: 0.12 *(0.04$ to 0.20$)$ & \\
\hline Total effect & $\mathrm{M} 1:-0.72 *(-0.98$ to 0.46$)$ & 0.16 & $\mathrm{M} 1: 0.64^{*}(0.35$ to 0.93$)$ & 0.154 & $\mathrm{M} 1: 0.37^{*}(0.23$ to 0.50$)$ & 0.16 \\
\hline \multicolumn{7}{|c|}{ Leads of equality of opportunity } \\
\hline Contemporaneous & M2: $-0.20^{*}(-0.34$ to 0.06$)$ & & M2: $0.15(-0.03$ to 0.33$)$ & & M2: $0.07(-0.02$ to 0.157$)$ & \\
\hline Five years older & M2: $-0.06(-0.22$ to 0.10$)$ & & M2: $0.22 *(0.03$ to 0.41$)$ & & M2: $0.08(-0.02$ to 0.175$)$ & \\
\hline Ten years older & $\mathrm{M} 2:-0.09(-0.23$ to 0.06$)$ & & M2: $0.23 *$ (0.06 to 0.40$)$ & & M2: $0.10 *(0.01$ to 0.181$)$ & \\
\hline Total effect & M2: $-0.35^{*}(-0.61$ to 0.09$)$ & 0.09 & M2: $0.60 *$ (0.28 to 0.92$)$ & 0.108 & M2: $0.24 *(0.09$ to 0.401$)$ & 0.10 \\
\hline
\end{tabular}

Total number of observations is 1000 ( $\mathrm{N}$ is lower than in previous tables due to inclusion of lags). Cls are computed using heteroskedasticity-robust SEs corrected for clustering at the age group-year level. Regressions are population weighted. Regressors from ESS are additionally design-weighted. All models include year, age group and country fixed effects and all controls described in Methods section and in table 1. Reported $R^{2}$ are 'within' $R^{2}$. Significant associations (uncorrected, at $5 \%$ level) are shown in bold.

Analyses were conducted using the REGHDFE Stata package ${ }^{42}$.

*Significant at table-wide false discovery rate of $5 \%$ (using Benjamini-Hochberg method).

ESS, European Social Survey.

of death by the ICD-10 classification of mortality. Three major causes were significantly associated with at least two measures of equality of opportunity. First, mortality due to diseases of the nervous system and the sense organs was associated with both the attainment of the bottom quartile $(\beta=-0.28, \mathrm{CI}=-0.48$ to -0.09 ) and the correlation between parental and children's socioeconomic status $(\beta=0.16, C I=0.06$ to 0.26$)$. Second, mortality due to diseases of the respiratory system was related to all three measures of equality of opportunity (eg, $\beta=-0.46, \mathrm{CI}=-0.76$ to -0.16 in model 7 ). Finally, mortality due to external causes was linked to the attainment of the bottom quartile $(\beta=-0.25$, $\mathrm{CI}=0.44$ to 0.07$)$ and the overall correlation of parental and children's socioeconomic status $(\beta=0.14, \mathrm{CI}=0.02$ to 0.25$)$.

\section{Lags and leads in equality of opportunity}

Table 4 demonstrates how mortality rates were associated with equality of opportunity observed in older and younger age groups. The sum of the lags/leads and the contemporaneous estimates gives the total effect of equality of opportunity. The contemporaneous measures of equality of opportunity remained significant when models included lags in equality of opportunity. Each lagged coefficient had the same sign as contemporaneous equality of opportunity. All lags but one were statistically significant. This resulted in much larger total effects for equality of opportunity than those reported in table 2. These estimates imply that, for example, a 1 SD change in the attainment of the bottom quartile was associated with a $3.9 \%$ change in mortality. Including leads in equality of opportunity yielded comparably large total effects for the attainment of the top quartile, but not for our other measures.

\section{Robustness checks}

We conducted a number of robustness checks, which are shown in online supplementary materials. First, we re-estimated the CIs for the presented point estimates via bootstrapping (online supplementary tables S3-S5). Second, we removed from the sample those cases in which our three measures took values beyond what was expected by full equality of opportunity (81, 23 and 18 observations were respectively removed for each measure of equality of opportunity from online supplementary table S6). Third, we verified that our results were unaffected by survey year-age group-country units with very few micro-level observations (ie, less than 50, resulting in 84 fewer macro-level observations in online supplementary table S7). Fourth, to test a potential issue with overcontrolling, we re-estimated the main results without accounting for the proportion of those with higher education (online supplementary tables S8-S10). Fifth, we fitted gender-specific models for cause-specific mortality as well as models that simultaneously included lags and leads in our measures of equality of opportunity (online supplementary tables S11-S15). These tests resulted in similar findings compared with those reported in the main analysis.

\section{DISCUSSION}

The operationalisation of equality of opportunity in this study complements measures used in previous research for the USA. We explored mortality outcomes not only with respect to the attainment of individuals coming from the lowest quartile of socioeconomic status but also how the attainment of individuals coming from the highest quartile of socioeconomic status and the overall intergenerational correlation in socioeconomic status were associated with mortality in 30 European countries.

We found that equality of opportunity, particularly the attainment of the lowest quartile and the overall intergenerational correlation in socioeconomic status, was negatively related to mortality rates. We also identified significant gender differences. All our measures of equality of opportunity were more consistently linked to mortality of men than that of women, suggesting that equality of opportunity primarily affects men's, rather than women's, health. There may be multiple reasons for this gender difference. Past research suggests that women's and men's mobility experiences differ significantly and that women's life chances are less strongly related to their social origins and are more likely to be shaped by other conditions, such as marriage markets, than is the case for men's life chances. ${ }^{33} 34$ Further, men and women also tend to differ in their understanding and assessment of the causes behind their own successes and failures in life. ${ }^{35}$ For instance, it might be that men who live in environments with higher equality of opportunity and who experience 
upward intergenerational mobility are more likely than women to exhibit lower levels of psychological distress. ${ }^{10}$

Differences in relation to the associations between equality of opportunity and specific causes of mortality can also inform our understanding of the mechanisms behind these associations. First, common modifiable causes of chronic respiratory diseases, such as tobacco use, unhealthy diet, physical inactivity, indoor and outdoor air pollution, allergens or occupational agents, are well known. ${ }^{36}$ Low equality of opportunity might cause individuals born into disadvantaged circumstances to be exposed to such stressors for longer and thus to have a higher likelihood of developing respiratory diseases. Our second significant cause, diseases of the nervous system and the sense organs, is also largely shaped by social determinants. Smoking, diabetes and environmental risk factors, such as exposure to pesticides, are important explanations, while stress, physical inactivity and regular alcohol consumption are all risk factors for vascular disorders and one of its main components-vascular dementia. ${ }^{37}$

Perhaps the most explicit theoretical channel linking equality of opportunity and mortality is the last significant group of causes of mortality, which consist of deaths due to external causes, including intentional self-harm and assaults. The limited chances of upward social mobility are likely to be viewed even more unfair than high economic inequality in itself. ${ }^{38}$ With the same mechanisms as the extensively investigated consequences of income inequality, ${ }^{39}$ inequality of opportunity can affect suicidal behaviour through psychological aspects such as depression caused by hopelessness, economic stress and anxiety about future. Further, inequality of opportunity can facilitate tensions and consequently violence in society if individuals perceive their lack of upward mobility chances as unfair and unjust. ${ }^{14}$

Our findings in relation to the effects of lags and leads in equality of opportunity did not confirm that the main channel linking equality of opportunity and mortality runs through individuals' greater investment aspirations in health, as determined by prospects of upward mobility, which we operationalised as equality of opportunity among older age groups. The results, however, suggest that retrospective equality of opportunity for younger generations is more consistently associated with mortality rates than the prospective equality of opportunity of older generations. This may be explained via spillover effects, in which equality of opportunity among younger generations affects the health of older generations. A complementary explanation is that equality of opportunity for younger generations is indicative of intergenerational mobility patterns, which individuals themselves experienced in the past.

\section{Limitations}

The main limitation of this study is that we could not directly test the causal associations between equality of opportunity and mortality, but we doubt that data which would allow for the direct estimation of causal effects exist. Such data would have to include an exogenous shock that affects nothing but equality of opportunity. Neither conceptually nor empirically can we think of such a type of shock. In addition, low sample sizes used to compute measures for our 1200 units of analysis, and other well-known limitations of survey data (eg, unaccounted for nonresponse bias) could affect our results. Moreover, mortality rates are the only cross-nationally comparable administrative data for specific age groups across time in Europe. This is the main reason why we were unable to account for any other covariates of mortality based on administrative data. Future studies, instead of accounting for country fixed effects, might also investigate if the

\section{What is already known on this subject}

- The association between individuals' social mobility and health is well established. However, how the health consequences of individuals' intergenerational mobility translate into macro-level associations between equality of opportunity and mortality is imperfectly understood.

- Pioneering research for the USA suggests that county-level intergenerational income mobility is negatively associated with mortality. No other evidence from different countries exists to date.

\section{What this study adds}

- We explored how the attainment of individuals socioeconomic status relative to their parents' socioeconomic status was associated with mortality in 30 European countries and found that equality of opportunity was negatively related to mortality rates.

- Intergenerational equality of opportunity was more consistently linked to mortality of men than that of women and especially to mortality due to external causes, including intentional self-harm and assaults.

- Our findings allow us to conclude that equality of opportunity is not only fair but it is also good for health.

links between equality of opportunity and mortality are moderated by specific contextual characteristics at the macro-level.

\section{CONCLUSION AND POLICY IMPLICATIONS}

Our finding that equality of opportunity is significantly associated with mortality, together with earlier evidence from the USA, allows us to conclude that equality of opportunity is not only fair but it is also good for health. Therefore, measures that aim at tackling barriers of various kinds that prevent population groups with disadvantaged social origins from experiencing intergenerational social mobility can be justified not only in virtue of normative considerations of equality of opportunity but also in terms of individuals' chances to enjoy long and healthy lives.

Acknowledgements The authors would like to thank attendees and discussants at various presentations of this study, especially at the 2019 British Sociological Association's Annual Conference, as well as Aaron Reeves and the three anonymous JECH reviewers for constructive comments and suggestions.

Contributors $A G$ and $C K$ devised the study. AG and CK acquired and prepared the data. AG and CK conducted the analyses and interpretation of data. AG and CK wrote the manuscript.

Funding Authors acknowledge financial support from the Oxford University Press John Fell Fund-reference number 162/037

Disclaimer The sponsor did not play any role in study design; in the analysis and interpretation of data; in the writing of the report and in the decision to submit the article for publication.

Competing interests None declared.

Patient consent for publication Not required.

Ethics approval This study did not require ethical approval as it used publicly available secondary survey and administrative data.

Provenance and peer review Not commissioned; externally peer reviewed.

Data availability statement Data are available in a public, open access repository.

Open access This is an open access article distributed in accordance with the Creative Commons Attribution Non Commercial (CC BY-NC 4.0) license, which 
permits others to distribute, remix, adapt, build upon this work non-commercially, and license their derivative works on different terms, provided the original work is properly cited, appropriate credit is given, any changes made indicated, and the use is non-commercial. See: http://creativecommons.org/licenses/by-nc/4.0/.

\section{ORCID iDs}

Alexi Gugushvili http://orcid.org/0000-0002-3933-9111

Caspar Kaiser https://orcid.org/0000-0003-3945-9137

\section{REFERENCES}

1 Ludwinek A, Anderson R, Ahrendt D. Social mobility in the EU. Dublin, 2017

2 Narayan A, der WRV, Cojocaru A, et al. Fair progress? Economic Mobility across generations around the World. Washington, DC: The World Bank, 2018.

3 Corak M, Inequality I. Income inequality, equality of opportunity, and intergenerational mobility. J Econ Perspect 2013;27:79-102.

4 Jerrim J, Macmillan L, Inequality I. Income inequality, intergenerational mobility, and the great Gatsby curve: is education the key? Social Forces 2015;94:505-33.

5 Chetty R, Grusky D, Hell M, et al. The fading American DREAM: trends in absolute income mobility since 1940. Science 2017;356:398-406.

6 Chetty R, Hendren N, Kline P, et al. Where is the land of opportunity? the geography of intergenerational mobility in the United States *. Q J Econ 2014;129:1553-623.

7 Venkataramani AS, Chatterjee P, Kawachi I, et al. Economic opportunity, health behaviors, and mortality in the United States. Am J Public Health 2016;106:478-84.

8 Venkataramani AS, Brigell R, O'Brien R, et al. Economic opportunity, health behaviours, and health outcomes in the USA: a population-based cross-sectional study. The Lancet Public Health 2016;1:e18-25.

9 O'Brien RL, Venkataramani AS, Tsai AC. Economic mobility and the mortality crisis among US middle-aged whites. Epidemiology 2017;28:e12-13.

10 Gugushvili A, Zhao Y, Bukodi E. 'Falling from grace' and 'rising from rags': Intergenerational educational mobility and depressive symptoms. Soc Sci Med 2019;222:294-304

11 Präg P, Richards L. Intergenerational social mobility and allostatic load in Great Britain. J Epidemio/ Community Health 2019;73:100-105.

12 Grossman M. On the concept of health capital and the demand for health. Journal of Political Economy 1972;80:223-55.

13 Wilkinson RG, Pickett K. The spirit level: Why more equal societies almost always do better. London; New York: Allen Lane, 2009.

14 Houle C. Social mobility and political instability. J Conflict Resolut 2019;63:85-111.

15 Breen R. Social Mobility in Europe. Oxford; New York: Oxford University Press, 2004.

16 Gugushvili A. Political democracy, economic liberalization, and macro-sociological models of intergenerational mobility. Soc Sci Res 2017;66:58-81.

17 Pförtner T-K, Günther S, Levin KA, et al. The use of parental occupation in adolescent health surveys. An application of ISCO-based measures of occupational status. J Epidemiol Community Health 2015;69:177-84.

18 Hallqvist J, Lynch J, Bartley M, et al. Can we disentangle life course processes of accumulation, critical period and social mobility? an analysis of disadvantaged socioeconomic positions and myocardial infarction in the Stockholm heart epidemiology program. Soc Sci Med 2004;58:1555-62.

19 Kelly-Irving M, Lepage B, Dedieu D, et al. Adverse childhood experiences and premature all-cause mortality. Eur J Epidemiol 2013;28:721-34.
20 Rieker PP, Bird CE, Lang ME. Understanding Gender and Health: Old Patterns, New Trends, and Future Directions. In: Bird CE, Conrad P, Fremont AM, eds. Handbook of medical sociology. Nashville: Vanderbilt University Press, 2010.

21 Johnson NJ, Backlund E, Sorlie PD, et al. Marital status and mortality. Ann Epidemiol 2000;10:224-38.

22 Lager ACJ, Torssander J. Causal effect of education on mortality in a quasi-experiment on 1.2 million Swedes. Proc Natl Acad Sci U S A 2012;109:8461-6.

23 Tapia Granados JA, House JS, Ionides EL, et al. Individual Joblessness, contextual unemployment, and mortality risk. Am J Epidemiol 2014;180:280-7.

24 Nandi A, Glymour MM, Subramanian SV. Association among socioeconomic status, health behaviors, and all-cause mortality in the United States. Epidemiology 2014;25:170-7.

25 Bandyopadhyay S, Green E. Urbanization and mortality decline. J Reg Sci 2018;58:483-503

26 Rognerud MA, Zahl P-H. Social inequalities in mortality: changes in the relative importance of income, education and household size over a 27-year period. Eur J Public Health 2006;16:62-8.

27 Modig K, Talbäck M, Torssander J, et al. Payback time? influence of having children on mortality in old age. J Epidemiol Community Health 2017;71:424-30.

28 Kawachi I, Kennedy BP, Lochner K, et al. Social capital, income inequality, and mortality. Am J Public Health 1997:87:1491-8.

29 Cockerham WC, Hinote BP, Cockerham GB, et al. Health lifestyles and political ideology in Belarus, Russia, and Ukraine. Soc Sci Med 2006;62:1799-809.

30 Scott AP, Timæus IM, differentials M. Mortality differentials 1991-2005 by selfreported ethnicity: findings from the ONS longitudinal study. J Epidemio/ Community Health 2013;67:743-50.

31 Clark KM, Friedman HS, Martin LR. A longitudinal study of religiosity and mortality risk. J Health Psychol 1999;4:381-91.

32 Stock JH, Watson MW. Heteroskedasticity-robust standard errors for fixed effects panel data regression. Econometrica 2008;76:155-74.

33 Ermisch J, Francesconi M, Siedler T. Intergenerational mobility and marital sorting. Econ J 2006;116:659-79.

34 Tyree A, Treas J. The occupational and marital mobility of women. Am Sociol Rev 1974;39:293.

35 Mezulis AH, Abramson LY, Hyde JS, et al. Is there a universal positivity bias in Attributions? A meta-analytic review of individual, developmental, and cultural differences in the Self-Serving Attributional bias. Psychol Bull 2004;130:711-47.

36 WHO. Global surveillance, prevention and control of chronic respiratory diseases: a comprehensive approach. Geneva: World Health Organisation, 2007. http://www. who.int/gard/publications/Risk factors.pdf

37 Sontheimer H. Diseases of the Nervous System. London: Academic Press, 2015.

38 Shariff AF, Wiwad D, Aknin LB. Income mobility breeds tolerance for income inequality: cross-national and experimental evidence. Perspect Psycho/ SCi 2016;11:373-80.

39 Pickett KE, Wilkinson RG. Income inequality and health: a causal review. Soc Sci Med 2015;128:316-26.

40 Hendrickx J. ISKO: Stata module to recode 4 digit ISCO-88 occupational codes; 2002.

41 Hout M. Getting the most out of the GSS income measures. Berkeley, 2004.

42 Correia S. REGHDFE: Stata module to perform linear or instrumental-variable regression absorbing any number of high-dimensional fixed effects. 2019. 